\title{
Principles of Participatory Research
}

Catherine Wilkinson, Faculty of Health and Social Care, Edge Hill University, UK, Catherine.wilkinson@edgehill.ac.uk, 01695657871

Samantha Wilkinson, Faculty of Science and Engineering, Manchester Metropolitan University, UK, Samantha.wilkinson@mmu.ac.uk, 01612476237

Abstract This chapter details the participatory approach to research, with an emphasis on active participation. The authors recognise the charm of participatory research as a process of mutual learning, whereby researchers become co-learners in children and young people's everyday lifeworlds, and children and young people become knowledgeable about social research methods, thereby developing their capacity and competence. Despite the benefits of participatory research, including claims that it is a more fair and equitable approach to research, the authors remain critical of the unresolved challenge of creating research equity. In particular, the authors are mindful of power structures in participatory research between adult researchers and children/young people participants, which are difficult to negotiate. This leads the authors to argue that participatory research should not be considered a cureall for adult-dominated research processes. The concerns documented throughout this chapter do not devalue the important role a participatory approach can play in knowledge exchange and action. Rather, they emphasise that implementation should not be without careful implementation.

Keywords: Children; Co-researchers; Participatory research; Power; Young people

\section{Introduction}

Since the 1990s, research with children and young people has witnessed significant changes in methods and epistemologies that have challenged traditional research methods (Weller 2006), and have endeavoured to dismantle conceptions of children as mindless and deviant (see Pain 2003). The literature has witnessed a surge in children-centred and, less so, young people-centred research methods. Such methods endeavour to remedy power inequities by supporting young people to choose their own methods of communication (Weller 2006). This 
is in line with the emphasis within social sciences upon young people's agency (e.g. Holloway and Valentine 2000). Alongside this movement, participatory research has gained increasing popularity (Wright et al. 2006) and can be seen as an effective, and more inclusive, way of engaging hard-to-research populations in the research process.

At its most basic, participatory research involves those conventionally 'researched' in the different phases of a study: for instance, in the construction of data (Gallagher 2008); presentation of research findings and dissemination (Pain 2004); and the pursuit of follow-up action (Cahill et al. 2007a). Though ostensibly related to ethnographic research, participatory methods are positioned as less invasive than traditional ethnographies, as participants assume an active role in the research process. Ideally, participants not only provide, collect, analyse and interpret data gained through participatory research, but they take action on issues and problems that arise (Pain and Francis, 2003). At their best, participatory research methods work with participants to produce change (Pain and Francis, 2003). It is for this reason that many authors (e.g. Crivello et al. 2009; Grasser et al. 2016) support participatory research, believing that when children and young people are involved in research, they have greater opportunities to influence decisions that concern their lives.

This chapter details the participatory approach, with an emphasis on active participation. It then provides an overview of different 'types' of participatory research, before discussing shared meanings and co-construction through participatory approaches to research. This chapter then turns to discuss social mores and power structures, and then choice and agency in participatory research with children and young people. It then offers key advice to researchers and practitioners considering implementing a participatory design; in doing so, it problematises the alleged emancipatory potential of participatory research. After concluding,

the authors provide some useful resources for researchers and practitioners considering implementing a participatory design.

\section{Participatory Approach, Active Participation}

The emergence of the sociology of childhood has contributed to a reassessment of the inclusion and role of children in research (Clark 2010). Children's right to participate in decisions that affect them (outlined in Article 12 of the United Nations 1989 Convention on 
the Rights of the Child) gives momentum (both political and quasi-legal) to the promotion of research which engages children and young people, particularly in studies about their lives (Holland et al. 2010; Graham et al. 2016). Adopting the view that children are competent and have an entitlement to participate has challenged researchers to (re)consider the most appropriate ways to enable and support their participation (Graham et al. 2016). While the United Nations (1989) Convention on the Rights of the Child does not refer specifically to research, it is applicable considering children's competence and ability to participate more generally.

Participation, according to Vromen (2003:82-83), is "acts that can occur, either individually or collectively, that are intrinsically concerned with shaping the society that we want to live in". In the context of research, participation is concerned with: who is involved throughout the research process (e.g. academic partners, organisations, children/young people), to what extent they participate, and to what end (Paradiso de Sayu and Chanmugam 2016). The term 'participatory research' originated from Tanzania in the 1970s, and is entrenched in work with marginalised, hard-to-reach, and oppressed people living in developing areas. Participatory research has since been developed and has been employed in a number of settings including healthcare, community development and education, and has been adopted and appropriated by scholars in a range of disciplines including anthropology, sociology, geography, and nursing. Participatory approaches are now widely employed by child rights advocates, critical educators, youth workers, and community organisers.

Researchers are faced with a challenge to maintain academic rigour throughout their research, whilst ensuring their research, and the emergent findings, is relevant to the real world (Foth and Axup 2006). Participatory research has been positioned as one way to achieve this social relevance and rigour. This is because participatory research is conducted in partnership with the individuals or community of interest - that is with them, and not on them (Orlowski et al. 2015). The bedrock of participatory research is that it involves those conventionally 'researched' in specific aspects of/all stages of research, from the definition of a problem or issue, through to dissemination and follow-up action (Pain 2004). It is an orientation to research focussed on the co-construction of knowledge through partnerships between researchers and those affected by/involved in the phenomenon under study (Sutton 
2009). In participatory research, then, the researcher is not responsible for producing knowledge; they must facilitate project partners to produce knowledge about themselves and their lives (Gallagher 2008). There are different levels of engagement within participatory research, varied both in methodological approach and scope. Franks (2011:15) proposes the idea of "pockets of participation", to refer to the different participatory elements that may comprise a project which children and young people can opt into.

Whereas children and young people were previously considered passive, or at best marginal, in research encounters, participatory research positions them as co-creators of knowledge. As Foth and Axup (2006:93) put it: "the core idea of participation is to shorten the communicative distance between research activity and real world activity, between researcher and researched". Participation has become a label that is haphazardly used, and is being implemented in a proliferating fashion in a number of domains across the world (Barreteau et al. 2010), for instance 'public participation; 'participatory budgeting'; 'participatory culture'. However, the widespread use of this word is accompanied with a caution that participation is being used to co-opt people into the agendas of others (potentially researchers, universities, or governments), or to justify short-cut research with a top-down approach (see Le De et al. 2015). This is problematic as participatory research should enable people to discover their own solutions according to their own priorities.

Participatory research is an approach to research (as opposed to a method per se). A variety of qualitative and quantitative methods can be employed within this approach, typically determined by the research context and discussions with project partners. Examples of methods used in combination with a participatory approach include, but are not limited to: participant observation; interviews; focus groups; surveys; child-led photography; child-led tours; theatre; map making; map labelling; diagramming; and drawing. Participatory researchers may adapt and appropriate methods, using them in new contexts, in new ways, or attempting to 'make them' participatory or relevant to bottom-up research. To provide an example, although a survey may not immediately be considered a participatory method, the design of the survey with project partners, including thinking up questions, undertaking the dissemination of the survey, and the analysis of the results, can be undertaken in a 
participatory fashion. Likewise, project partners can be involved in peer interviewing and facilitating focus groups.

For participatory research with children and young people, often methods are employed to draw on skills possessed by the age group. For instance, older children may be involved in methods such as completing diaries and story-writing, whilst younger children may be invited to participate in drawing activities. Accommodating different skill sets is important as young people are a highly differentiated group, and approaches that are appropriate for children may be unsuitable or unacceptable for teenagers, and vice versa. This emphasises the importance of a 'mosaic approach' developed by Clark and Moss (2001) to elicit the perspectives of very young children about their day care experiences. This multi-method approach supports the use of both traditional and participatory tools to listen to children's views (each method or each person's perspective representing a tile in the mosaic). Multiple methods allow researchers to be as inclusive as possible and "play to" children's strengths (Clark 2010:118). A further example of this is that, in research with young people, methods are often selected based on the assumption that young people are digital natives. However, there is evidence that young people involved in research do not always prefer the methods that adult researchers assume they will. For instance, in Wilkinson, S.'s (2015) research into young people's alcohol consumption experiences, the researcher presented young people (aged 15-24) with the option of completing an audio or written diary. She anticipated that the young people would opt for the audio method, believing that they may perceive the written diary as a form of homework. Further, Wilkinson, S. (2015) considered that the audio diary was in line with young people's typical confidence in using technology. Much to her surprise, all young people opted for the traditional paper-based diary, contending that they 'don't like the sound of their own voice', and described the prospect of using the audio-recording device as 'scary', fearing they may accidentally delete something. Having a palette of methods that participants can opt into thus acknowledges that any one research activity or tool will not be accessible or appealing to all children and young people with different skills, cultural backgrounds and personalities.

Further, as Crivello et al. (2009:56) reflect, selecting methods for children often takes into consideration the "fun factor" of these methods, acknowledging that children may have lower attention spans for research than do adults. This 'fun factor' runs alongside the idea that early 
childhood research has been at the front of participatory approaches intended to ensure that children's involvement in research is appropriate, safe, enjoyable and meaningful (Graham et al. 2016). As Pinter and Zandian (2015) point out, creative participatory methods can provide heightened opportunities for enjoyment, education and a sense of empowerment. Importantly, however, though potentially enjoyable, adopting creative participatory methods does not guarantee that young people have genuine opportunities to develop and perform agency throughout a research project (Waller and Bitou 2011). To explain, the success of the implementation of these methods is, in part, related to the positionality of the adult researcher. There are arguments that researchers should adopt the 'least adult' role (see Randall 2012), and debunk children's impressions of the powerful and "potentially dangerous" researcher (see Phelan and Kinsella 2013:85). However, others (e.g. Ansell 2001) caution that equal research relationships are impossible. There will be more discussion of this in the Social Mores and Power Structures section later in this chapter.

Just like traditional research projects, participatory research projects require significant levels of energy prior to the commencement of the project, including responding to a funding call, or proactively writing a funding application to undertake a project. As an outline of the study and research questions are typically a necessary part of a funding application (to demonstrate to the funder what, precisely, the project will seek to undertake), most often children and young people/other project partners are not involved in the early stages. An exception to this is health research which often does involve patients and public in setting research priorities and also in developing bids, designing tools, and influencing the aims of studies (see Bird et al. 2013). In many other disciplines, writing the funding bid and applying for funding is undertaken by the adult researcher(s). This is perhaps because adult researchers are aware of the competitiveness of funding and the strict criteria that must be met, and have learnt from experience/training what precisely to include/address within a written bid. In this sense, most studies only become participatory once the project has been approved by a funder (McCartan et al. 2012). This begs the question, then, to what extent is participatory research a tokenistic gesture? Further, is participatory research really addressing the concerns of those at the centre of the research, or the researcher's own agenda? 
Considering the extent of children and young people's participation in research, Hart (1992) developed a 'ladder of participation'. The creation of the ladder was part of a global drive for participation (Funk et al. 2012), and has been adopted by groups and institutions that use it to think about how they work with young people, including youth workers; scout leaders; and health professionals. Hart's (1992) ladder presents participation as a continuum, reflecting that children may participate to varying degrees at different stages of a project. The ladder is comprised of eight rungs, ranging from three types of 'non-participation' including manipulation, decoration and tokenism, through to five types of participation. At the top of the ladder is child-initiated shared decisions with adults, where children have ideas, set up the project and invite adults to join with them in making decisions. See figure 2.1:

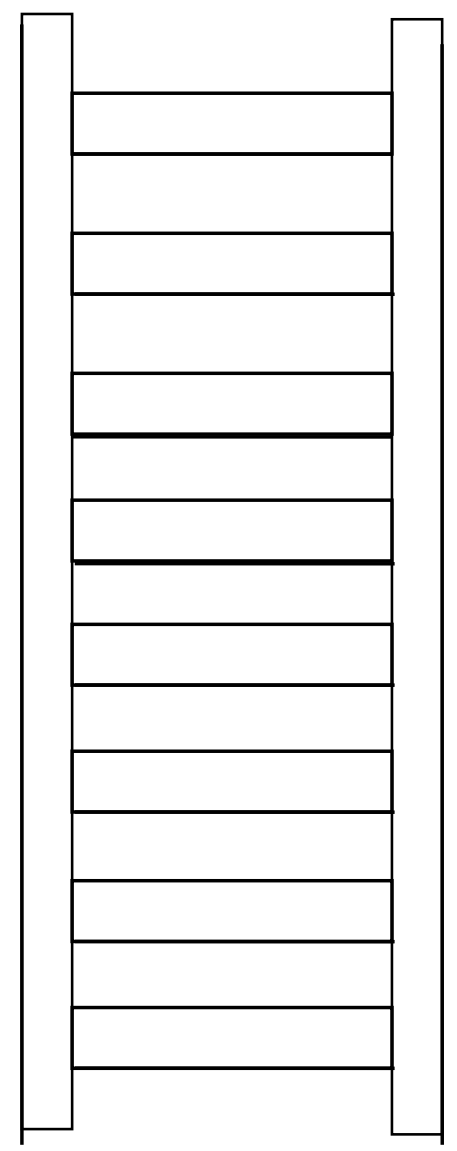

Rung 8: Young people and adults share decision-making

Rung 7: Young people lead and initiate action

Rung 6: Adult-initiated, shared decisions with young people

Rung 5: Young people consulted and informed

Rung 4: Young people assigned and informed

Rung 3: Young people are tokenised

Rung 2: Young people are decoration

Rung 1: Young people are manipulated

Fig. 2.1: Ladder of participation (adapted from Hart 1992)

Though useful, the ladder of participation should not be used as a measuring stick of the quality of any research project. As Hart (1997) recognises, the ability of a child to participate 
varies greatly with his/her development: a preschool child may be only capable of carrying materials to a playground building site, whereas an adolescent might be able to oversee the entire building operation. Further, it is not necessary that children always operate on the highest rungs of the ladder. This relates to a critique that the ladder structure is hierarchical (Hart et al. 2004), which is likely to lead to participatory activities being unfairly and misleadingly judged against particular levels. Gristy (2015:371) tells how the project she was involved in was defined as 'participatory' in its early phases, but this position changed as the project developed, with "the contingent shifting relations with, within and between the project, the young people involved and the researcher". Gristy's (2015) aim was for young people to be involved in every element of the planning and implementation, however she later began to question her motivations and the appropriateness of a participatory approach, recognising that the young people in her research project wanted action quickly, which the participatory research process did not lend itself to. This emphasises that different young people, at different times, might prefer to perform with varying degrees of involvement or responsibility.

Moving on from Hart's (1992) ladder of participation, Treseder's (1997) model of participation reworks the five degrees of participation in two ways. Firstly, it aims to communicate that there is not a progressive hierarchy or a particular sequence in which participation should be developed. Second, there is no limit to the involvement of children and young people, but children and young people must be empowered adequately to enable full participation (see Treseder 1997). An alternate model is Shier's (2001) Pathways to Participation diagram, intended as a practical planning and evaluation tool to be applied in situations where adults (typically teachers/schools) work with children. The pathways framework, like Hart's (1992) ladder, highlights the relationships between different levels of participation and the stages within each. Its purpose is to help adults to identify and enhance the level of children and young people's participation in line with the five levels of participation. At each level, adults may have differing levels of commitment to the processes. The levels of participation range from when children and listened to, to children sharing power and responsibility for decisionmaking. Three stages of commitment are identified across the top of the matrix: openings, opportunities and obligations (see Shier 2001). Pathways to Participation makes no suggestion that young people should be pressured to participate in ways and levels they do 
not want, or that are inappropriate for their level of development and understanding (Shier 2006). However, some commentators (e.g. Sinclair 2004) argue that the hierarchical nature of Pathways to Participation pushes teachers and schools to move relentlessly from the lower levels to the higher, and thus it has the same trappings as Hart's (1992) ladder of participation.

Having provided an outline of the participatory approach, this chapter now turns to detail different types and purposes of participatory research.

\section{Types and Purposes}

Participatory research is an umbrella term referring to a range of methodologies and epistemologies that aim to produce or inspire change for, and importantly with, project partners (Pain and Francis, 2003). A number of research methodologies have been created or adapted to encourage participation (Foth and Axup 2006), and the diversity of participatory approaches is growing. Approaches used within the participatory paradigm include community-based participatory research (CBPR); participatory action research (PAR); participatory rural appraisal; user-centred design, and theatre for development, amongst others. As the most commonly employed approaches, CBPR and PAR will now be detailed, respectively, with a discussion of how they 'fit' with the ideal of participation.

\subsection{Community-based Participatory Research (CBPR)}

CBPR is an orientation to conducting participatory research, not a research method (Horowitz et al. 2009). It involves conducting research equitably through partnerships between researchers and communities of people directly affected by, and thereby knowledgeable of, the context and culture that impact an identified subject, problem or concern (Horowitz et al. 2009). This collaborative approach involves all partners in the research process and recognises the unique strengths that each brings to the process of knowledge production (Horowitz et al. 2009). Horowitz et al. (2009) argue that in CBPR, the starting point is a topic of importance to the community, and this orientation aims to combine knowledge with taking actions, including social change. Researchers and funding institutions have requested 
increased attention to the issues that affect the health of children living in communities and have called for greater community involvement in processes that shape research and intervention approaches through CBPR partnerships among academics, health services, public health and community-based organisations (Israel et al. 2005).

The term 'Community' in CBPR is typically interpreted broadly, considering anyone who will be affected by the research; it could be geographic, virtual, identity-based, a community of interest, or other type of community (Horowitz et al. 2009). Community participation in research is useful for ensuring that the aims and objectives of the study are relevant to the community, and that the means of accomplishing them (including methods, timeframes and resources) are realistic (Horowitz et al. 2009). However, fostering meaningful communitybased participatory relationships between researchers and the community can be challenging (Tucker et al. 2016). Often such relationships can become muddled, and it is not uncommon to hear of CBPR "gone wrong" (Mayan and Daum 2016:69). Tucker et al. (2016) argue that relationships between researchers and the community cannot be forced and that they must be allowed to develop organically, much like a social relationship, thereby fostering trust. If successfully developed over the long-term, equitable partnerships can lead to a number of benefits, including the sustainability of these relationships, generating spin-off research projects, cultural shifts and the implementation of new policies (Jagosh et al. 2015), as well as giving rise to rigorous processes and yielding rich data (Mayan and Daum 2016). Importantly, young people are less likely to be included as partners in CBPR, owing to a belief that young people seldom feature as leaders of communities, groups, or organisations (Jacquez et al. 2013). However, this discredits or ignores the important roles that young people play as leaders in youth advisory groups and youth councils, for instance.

According to CBPR best practice, findings should be disseminated by, and to, all partners. Academic and non-academic project partners learn how to communicate effectively with each other's audiences, expanding their competences and skill sets, further strengthening relationships, and opening avenues for collaboration and the sharing of ideas (Horowitz et al. 2009). Strategies for dissemination at the local level include discussions within town hall meetings, presentations at local venues, and through community newsletters (Horowitz et al. 2009). It is also typical for the findings of CBPR to be translated into practice and policy. 
Furthermore, it is not unusual to see collaborators of CBPR projects (including children and young people) presenting at academic conferences.

Challenges include that CBPR is typically more time-consuming than traditional research, and therefore conducting research within a traditional research timeframe may not be possible, or may lead to compromise; partners may differ in their emphasis on project objectives and perspectives; there may be financial inequities, such as the difference in academic salary versus project partner 'incentives'; and involvement may be marginal or tokenistic (Horowitz et al. 2009). The CBPR approach is recommended to researchers who would like to increase the relevance, rigor, and results of their community-based work (Horowitz et al. 2009). CBPR is not, however, all about the outcome; advocates of CBPR (e.g. Flicker 2008) argue that the very process of meaningful participation can be transformative for project partners.

\subsection{Participatory Action Research (PAR)}

PAR arises from two research approaches: participatory research and action research. PAR is often used interchangeably with these two approaches, although the three should be understood as distinct approaches (sharing some commonalities). The main objective of PAR is social change (Cahill 2007a). As such, it is the 'action' that differentiates PAR from methodologies which primarily set out to 'investigate'. There has been a close relationship between PAR and marginalised and disenfranchised groups, and also of political and pedagogical projects. PAR is gaining increased attention in community and public health research (Khanlou and Peter 2005), and can involve qualitative, quantitative or combined data gathering methods, depending on the issue under investigation.

In PAR there is a commitment to research contributing to communities/groups and 'giving back' to collaborators (Pain 2004). The overarching aim of PAR is to 'give power to' groups of people/individuals who are seeking to improve their situation. To this end, PAR involves collaboration between researchers and stakeholders in the co-production of knowledge (Baldwin 2012). Baldwin (2012) describes how researchers and stakeholders join together to produce new knowledge to inform practice and solve identified problems. Thus, more than just being informative, PAR can be transformative (Baldwin 2012). As an epistemological 
choice, PAR is most closely aligned to social constructivism and critical theory (Langhout and Thomas 2010), maintaining the belief that all knowledge is socially created.

One of the ideals of PAR is that the beneficiaries should be directly involved in conducting the research. PAR may involve participants in any, or all, of the following: helping to formulate/identify the problem; assessing the problem; determining an intervention; and assessing the intervention (Langhout and Thomas 2010). PAR requires researchers to be more reflective, reflexive, and transparent about their respective standpoints, vulnerabilities, and the limits to different theories, methods, and analytical strategies that they adopt (Guishard 2009). Reflexivity is an awareness of how the researcher and objects of the study affect each other mutually throughout the research process (Berger 2015). Warin (2011:810) explains that it is necessary to develop "an interdependent awareness" of how the researcher influences research participants' perceptions, and also of how participants influence the researcher. Further, reflexivity provokes researchers to remain open to that which is not yet known, trying to avoid bringing their own epistemologies to bear on the data (Graham et al. 2016). This is further complicated as the 'researcher' in PAR projects is not a lone investigator but individuals in a collective. PAR is therefore a process augmented by the multiple perspectives of several researchers (academic and non-academic) working together (Cammarota and Fine 2008). The intimacy of a PAR approach has brought its own problems; PAR researchers have reflected on their positionality, and the blurring between researcher and friend (e.g. Guishard 2009; Wilkinson 2016) in building relationships with project partners.

Despite a number of differences in participatory research designs, many key facets are similar, mostly linked to co-production. Before moving on to unpack participatory research further, it is important to remember that participatory approaches are not appropriate for all types of research (see Gristy's 2015 discussion of 'moving on' from participatory research). The suitability of any one methodology depends on the purpose of the research. Having detailed some of the different types of participatory research, this chapter now turns to unpack shared meanings and co-construction which characterise a participatory research approach. 


\section{Shared Meanings, Co-construction}

As discussed thus far in this chapter, the defining characteristic of participatory research is not so much the methods and techniques employed, but the degree of engagement of participants within, and beyond, the research encounter (Pain and Francis 2003). Participatory research is characterised by shared meanings and the co-construction of knowledge, and thus the emphasis is on research with, as opposed to on, participants.

It is appropriate here to draw on Chávez and Soep's (2005) exploration of the collaboration among young people and adult participants at Youth Radio, a broadcast training program. The authors introduce the concept of 'pedagogy of collegiality' to describe how young people and adults at the training program are mutually dependent on one another's abilities, viewpoints, and combined efforts to engender original, multitextual, professional-quality work. Though not discussing participatory research specifically, Chávez and Soep's (2005) concept of pedagogy of collegiality is certainly relevant to the more nuanced analysis that can be produced through the relationship between young people and adults in participatory research. Collegiality is a relationship of shared collective responsibility. Collegial pedagogy, then, characterises situations in which young people and adults jointly identify the area of focus and undertake projects in a relationship marked by interdependence, where both young people and adults are hands-on and applied in their contribution (Chávez and Soep 2005). In particular, striking similarities can be seen between collegial pedagogy and PAR, as outlined in the previous section.

However, caution must be exercised when using the term 'collegiality' because it can suggest a utopian view of joint production, whereby young people and adults are equal co-producers, democratically creating work together (Chávez and Soep 2005). Chávez and Soep (2005) argue that the mutual engagement, investment, and vulnerability between young people and adults that underpin collegial pedagogy do not nullify the institutional and historical forces through which power travels in any collegial and pedagogical relationship. Participatory research, just like collegiality as described by Chávez and Soep (2005), involves the mobilisation of the skills, competences, knowledge and resources of project partners. In participatory research, 
children and young people are often employed as peer researchers because they possess skills that adult researchers do not; they speak the same language as their peers; they have access/membership to hard-to-reach groups, and they have first-hand insight into matters affecting their age group (McCartan et al. 2012). Essentially, they are experts in their lives (Mason and Danby 2011), capable of defining, exploring and finding solutions to their own problems. Thus, the knowledge produced from participatory research with children and young people can be considered more authentic, richer, and more reliable than that produced through traditional top-down practices.

This joint production/co-construction is complicated, however, as children and young people often do not possess the same level of data collection and analysis skills as researchers, who may have spent several years at university honing their skills. Enabling children and young people to develop the knowledge, skills and responsibility to co-construct research signals the "conscious exchange of power" (McCartan et al. 2012:10) between adult researchers and children/young people. Participatory research, then, increases children and young people's capacity to identify and solve problems affecting them. However, this is not without critique, and some authors have condemned such 'teaching' as implying that project partners would benefit from "superior" knowledge (see Ansell, 2001:103). Others instead argue that participatory research is a process of mutual learning (Ho 2013); whilst children and young people may be trained as peer researchers, developing skills in interviewing and facilitating focus groups (see e.g. Cahill 2007a), researchers become co-learners in their everyday lifeworlds (Minkler et al. 2002). Participant researchers have a role in data gathering and analysis (although less occasionally the latter). They can also influence how research findings are subsequently disseminated, and this is often in culturally credible ways. In sum, each person in the research partnership is considered to bring unique strengths and skills.

This intergenerational learning, where children and young people learn research skills through guided participation and active engagement (Langhout and Thomas 2010), and adults learn about young people's lifeworlds, can produce robust research. Further, the collaborative ethos of participatory research is significant for mutual capacity building. Selfconfidence is a reported outcome of participatory engagement with children/young people, as well as increased awareness and knowledge of the research topic, and social development 
related to working in a team (see Grasser et al. 2016). Importantly, undertaking participatory research with children/young people does not mean that adult researchers are abandoning their research roles, but allowing flexibility for the changing nature of their roles, with new opportunities for the co-construction of knowledge (Clark 2010). It is important for adult researchers to be willing to allow this transformative process. It has been argued that in participatory research guidelines can, and should, be developed to protect research (and researcher!) integrity (see Khanlou and Peter 2005). Such guidelines would pertain to aspects such as research design; individual roles and responsibilities within the research project; ownership and authorship; and dissemination (Khanlou and Peter 2005). Clearly, there is a difference between participation (taking part in) and effective participation (co-construction). This chapter now turns to consider social mores and power structures within participatory research with children and young people.

\section{Social Mores and Power Structures}

In traditional research, the researchers are powerful, because they determine the aims and objectives, methods and data collected, and therefore the knowledge produced (Gallagher 2008). It is argued that to progress beyond this unfair situation, some power must be taken away from adults and given to children/young people, so that power is distributed equally (Gallagher 2008). Participatory research is often suggested as a strategy to overcome power imbalances between researchers and research 'participants' because it values equally the knowledge of each individual who participates in the project (Dorozenko et al. 2016). Thus, participatory research with children and young people is characterised by a shift from the typical power dynamic inherent, to include children and young people as active researchers in one or more phases of the research process.

As has been argued so far throughout this chapter, participatory methodologies provide opportunities for children and young people to present their experiences and knowledge that is less likely to be mired by researcher concerns (Dentith et al. 2009). Participatory research attempts to minimise the "us and them" dichotomy between academic researcher and participants (Pain 2004:656). However, owing to the collaborative nature of the participatory process, power dynamics can be difficult to negotiate. DeLemos (2006) recognises the 
problems associated with renouncing total control in research. The author highlights the shifting power scales from research on communities to research with and for communities. By researching with children and young people, participatory research endeavours to break down the hierarchies of knowledge and democratise the research process: as Cahill (2007b:16) puts it, to move beyond the "privileged perspectives of the ivory tower". The multiple reported benefits of engaging children and young people in research have served to redistribute power within the research process and build the capacity of children and young people to not only analyse, but importantly to transform their own lives and become partners in the building of more sound, democratic communities (Cahill 2007b). As is clear from this, power and empowerment are central concepts in participatory research in reversing conventional assumptions about who owns and benefits from research (Pain 2004), and in promoting inclusion within the research encounter.

Certain authors have discussed how they attempted to "divest power" so that project partners could "take control of the research process" (Dorozenko et al. 2016:200), in a bid to move towards participatory research. However, this can lead to feelings of the loss of expert status for the researcher, and adopting a role of observer and facilitator (Dorozenko et al. 2010). There is a need to bridge participatory epistemologies with methods that support the transgression of power relations in research with young people. This rebalance promotes children and young people in a position of competence and power and compels researchers to abandon the traditional views of children/young people as vulnerable and incompetent (Sime, 2008). This requires researchers to reflect on their own subjectivities and the discursive relations of race, class, gender, sexuality, religion and age (Dentith et al. 2009). More than this, it requires researchers to reflect on other more movable aspects of their positionalities - including education, social position, occupation, and also their personality and appearance (see Wilkinson 2016). Exercising this reflexivity will enable power relations to be properly understood and negotiated. Some researchers (see Ansell 2001), however, have argued that power will always be present in the research relationship, and that adult researchers cannot avoid being in control of research agendas.

Participatory research is dependent on stakeholder input to obtain its applauded benefits of improved social significance, validity and actionability of research outcomes (Barreteau et al. 
2010). An often understated issue is that, for a number of reasons, children and young people may choose not to participate in a research project. Put more bluntly, the desire to participate in research must not be assumed. The meaning of participatory in 'participatory' research, then, should be determined in communication with the participants in one's proposed study; only then can such research be considered truly participatory. This chapter therefore argues that the degrees of expected participation should be negotiated at the outset, rather than imposed. Researchers and participants should communicate about precisely in what ways participants will be involved (Barreteau et al. 2010). As Cahill (2007b) has argued, the term 'participation' has been used indiscriminately, and there is a need to be wary about such broad applications of the term so that it is not used as a tokenistic gesture. Related to this is how use of the word 'participation' plays out in expectations; that is the expectations from researchers of participants, and vice versa. Perceptions of degrees of participation may vary between different actors. Barreteau et al. (2010) argue that disappointment experienced by participants can be avoided by being forthright about how participation will be implemented, and what kind of involvement (and how much) is expected. Thus, it is all about finding "appropriate and desirable levels of involvement" that give participants meaningful voice (if they so desire it) without overloading them or diverting them from other duties in their lives (Flicker 2008:84). The extent of collaborative involvement may vary over the duration of the project and from one project to the next, determined by the nature of the project (Jagosh et al. 2012). Equally, children and young people may have more time/desire to participate at one stage of a project than another, and this should be accommodated.

On the flip side to the overburdening of participatory research as described above, some children and young people may wish to participate in a research project further than the remit outlined by researchers allows. Barreteau et al. (2010) question whether participants will become sceptical after experiencing participatory processes that did not allow them to participate in the ways that they expected and, this chapter adds, to the extent they wish to participate. Thus, people who are disappointed while participating in a research project may be disinclined to continue, or reluctant to participate in future projects (Barreteau et al. 2010). Hence, Barreteau et al. (2010) argue that, when explaining the aims and approach of a potential participatory research project to prospective partners, and what their participation 
will entail, special attention must be given to who, ultimately, has control over the research process.

There are a number of obstacles relating to power and communication that encumber the task of involving children and young people as active participants in the research process. One, as challenged by Kellett et al. (2004:330) is the "competence barrier". Clark (2010) reports that the age and stage of development of a child (something touched upon previously in this chapter in relation to the choice of methods, and also Hart's 1997 ladder of participation) can put emphasis on the power differences between (adult) researcher and child/young person research participant. This stance is taken from a developmental psychology perspective, and is intrinsically related to age. For instance, Clark (2010:116) reports that young children can be seen as presenting "communication difficulties" in a research context due to their non-literature status. This power gap can be widened further if the child/young person belongs to other marginalised groups, taking into account gender, class, ethnicity, and disability. However, this dated view is being replaced (see Christensen and Prout 2002) with the idea that social experience should be a more reliable marker of competence than age.

In summary, it is often assumed that participatory research is a positive ethical and political framework for approaching research with children and young people. Above, we have demonstrated how arguments that suggest that power differentials between adult researcher and children/young people participants can be eliminated through participatory research are problematic (Pain and Francis 2003). This chapter now moves on to consider the related topics of choice and agency in participatory research.

\section{Choice and Agency}

Locating children and young people as active social agents via participatory methods to facilitate 'voice', 'agency' and 'empowerment' have been highlighted as influential in the early wave of childhood research (Holland et al. 2010). In the participatory research literature, 
there has been a tendency to theorise agency almost as an attribute that children/young people can 'have' and that is enabled, promoted or 'given' by the adult researcher (Grover 2004). This relates to a critique (e.g. Funk et al. 2012) that some participatory research projects involve children and young people as tokens, resulting in low levels of self-advocacy and empowerment. Thomson (2007) highlights how child-centred participatory approaches can cause harm if children's voices or perspectives are rendered inauthentic or meaningless, due to unacknowledged personal assumptions of the researcher; this resultantly keeps children 'in their place'. As Ansell (2001) argues, choices must be made by the researcher, and although the consequences of these choices cannot be fully controlled, nor fully known, some responsibility must be assumed for the potential outcomes.

As discussed above in this chapter, research should be a positive and empowering experience for children and young people (Sime 2008). By involving children and young people in the research process it is argued that they "cease being data mules in the carriage of other people's academic careers" (Smyth and McInerney, 2013:17-18), and instead are realised as competent actors in their own lifeworlds. Participatory research is not, as this chapter has begun to unpack, without its flaws. One argument is that, despite children and young people assuming a more active role in participatory research, the process can still be configured as adult-controlled (Morrow 2008; Sime 2008). For instance, Gallacher and Gallagher (2008) recognise that, whilst some participatory research does provide choice for children and young people, and opportunities to exercise their agency, much is highly managed by researchers. For instance, children and young people are often instructed on what to research, how many photographs to take, and of what subjects (Gallacher and Gallagher 2008). An exception of this is the work of Kellett et al. (2004:332), whereby children were given "completely free choice" in what they wanted to research and what methods to use; many children chose areas related to their interests and concerns.

Further, Mohan (1999:51) is concerned that: "despite replacing a monologue with polyphony there are still the questions of who writes up, who publishes the material and whose career benefits?" Mohan's (1999) account demonstrates the extent to which children and young people are often not given the choice to participate after the data gathering stage. Reflecting on a project that attempted to engage young people with an intellectual disability in 
participatory research, Dorozenko et al. (2016:200) argue that, as academic researchers, their team had "certain skills and expertise that lent itself to research". The authors explain that they are experienced at undertaking literature reviews, analysing qualitative data, and publishing research reports, and they felt it would be "self-effacing (and dishonest)" to deny their contribution to this part of the research project (Dorozenko et al. 2016:200). Muhammad et al. (2015:1055) support this, stating that, in the writing and representation of data, "academic power and privilege can become omnipresent", as academics have the training and expectations to produce peer-reviewed articles, whereas project partners may have distinct expectations (for instance, school/work) that preclude additional tasks. However, in 'true' participatory research, though possibly a utopian view, children and young people should be given the choice as to whether they wish to participate in these later stages of a project. Though not a conventional stance, there is much to be commended in Mary Kellett's decision to include three young people (Ruth, Naomi and Simon, aged ten) as coauthors in an article published in Children \& Society about empowering children as active researchers (see Kellett et al. 2004). Kellett enables children in this project to take ownership of their own research agendas, and challenges the status quo.

Discussions of choice and agency in participatory research speak to two main problems as identified by Gristy (2015): the problem of representation, and the problem of speaking for others. Any written reports emerging from the research activity that involve people will implicitly require representation. Further, Gristy (2015) argues that representation in a discursive context, such as communication of the findings of a project, is a political act. This is especially so when considering the different editorial decisions involved in publishing journal articles and book chapters, for instance choice of the venue to publish; word limits; restrictions to lengths of quotations etcetera that ultimately rely on the researcher to make decisions.

However, it should not be assumed that all young people are as 'hung up on' their representations as some researchers are on their behalf. Wilkinson C. (2015) undertook a participatory research project with young people at a community radio station, which involved the co-creation of an audio documentary and a radio series. She reflects how, in preparing for the audio documentary and radio series, conjuring up key themes, and thinking 
about songs and particular lyrics to be included, the young people were eager to participate. They were also forthcoming in volunteering their time to be interviewed, and assisting with use of the recording equipment. However, when it came to editing the audio clips, the young people seemed reluctant. Also discussing the co-production of an audio documentary, NoskeTurner (2012), too, reflects that editing, the phase that she had predicted as being crucial for participation in meaning-making, was met with the most ambivalence by participants. Considering that she desired to facilitate the presentation of youth voice and to promote agency, Wilkinson, C. (2015) was wary of making editing decisions independently. Aware of the potentially manipulative and exploitive editing process, accurately representing the young people was something that she aimed for. However, Wilkinson, C. (2015) was surprised that the rare occasions that young people requested the deletion of an audio clip was because they had made a slip of the tongue or stuttered over speech, and were embarrassed by this being broadcast. In other words, editing was only requested for issues surrounding delivery, as opposed to content. Thus, Wilkinson, C. (2015) concludes that her desire for the young people to have agency over their representations was greater than (or perhaps more accurately different to) theirs.

Also challenging the participation agenda, and perhaps on the flipside of the above argument, Lushey and Munro (2014) argue that co-producing research can be a burdensome and undesirable task, and consider it an unethical demand to expect un-salaried young people to have equal involvement in the project. Thus, although some scholars criticise participatory research as it does not devolve control of the research entirely onto participants, it should not be assumed that participants would want this control or responsibility. Involvement in any research project can be time-consuming, and participatory research, due to the process of co-production, can be even more burdensome. Thus, by insisting upon forms of participation, in the belief that it constitutes empowerment, researchers may actually be reproducing the regulation of children and young people (Gallagher 2008). Researchers must be prepared for the ways in which children and young people may utilise their choice and agency (granted to them by unsuspecting researchers) to exploit, appropriate, redirect, contest or refuse participatory techniques (Gallagher 2008). For instance, in Ansell's (2001) research which was concerned with co-producing knowledge about Third World Women, students in a Zimbabwean secondary school resisted her attempts to enrol them as 
researchers in her project. After co-operating in the preparatory phase during school time, none of the students conducted research out of school, and some even fabricated results/analysis to appease her. Ansell (2001) reflects how an exercise she considered empowering of the students was perceived by them as an unreasonable imposition on their time. Ironically, this exercise did allow the students to assert their agency though not in the way that Ansell (2001) had hoped (arguably, school is a location where children are least able to exercise their participation rights, Kellett et al. 2004). There is also the issue that what may be interesting to researchers might be 'boring' or too challenging (emotionally or intellectually) for young people, or any lay participants (Holland et al. 2010). There is a weak empirical base of what children and young people think and feel about being involved in participatory research (Hill 2006), despite an abundance of writing stating involvement in participatory research is 'good for them'. This emphasises the importance of allowing choice in the ways in which/the extent to which children and young people participate. This chapter now turns to offer some key advice both taken from the literature, and also that the authors have learnt from their own engagement (to varying levels of success) in participatory research.

\section{Key Advice/Points}

1. Participatory research is a process of mutual learning, and researchers must become co-learners in children/young people's everyday lifeworlds

2. Project partners must agree on the missions, goals and outcomes of participatory research at the outset

3. The meaning of 'participatory' in 'participatory research' should be determined in communication and negotiation with the children/young people in one's study

4. Participatory research should not be expected to eradicate power differentials; rather if successfully undertaken, it should minimise them

5. Sharing honest accounts of practice enables dilemmas in participatory research to be considered, thereby contributing to researcher learning 


\section{Conclusion}

Participatory research has been touted as a more empowering and equitable approach to research with different groups, including children and young people. Part of the charm of participatory research is that it is a process of mutual learning (Ho 2013), whereby researchers become co-learners in children/young people's everyday lifeworlds (Minkler et al. 2002), and children and young people become knowledgeable about social research methods, thereby developing their capacity and competence (Jagosh et al. 2012). Despite the benefits of participatory research, however, the unresolved challenge of creating complete research equity has several consequences.

Throughout this chapter, the alleged emancipatory potential of participatory research has been problematised. It has been argued that participatory research should not be considered as a cure-all for adult-dominated research processes. Particular concerns are centred on who benefits most from the undertaking of the research (i.e. the adult researcher's career or the child/young person's). Further, there is the potential for the reproduction of power differentials throughout the research process. As interest grows in collaborative research, it is important to support the development of new partnerships in line with the desire for more equitable forms of knowledge production.

The concerns documented throughout this chapter do not devalue the important role a participatory approach can play in knowledge exchange and action. However, it emphasises that this should not be without careful implementation. Efforts to increase the participation of children and young people in participatory research should be measured against their will to participate at different phases of the research. New understandings and appreciations of 'participation', and in particular meaningful participation, can bring exciting possibilities for research agendas. 


\section{Useful Resources}

\section{Participatory Research Hub at Durham University:}

The Participatory Research Hub at Durham University hosts free events and training sessions, as a way to share knowledge about 'doing' research that brings more equitable benefits to all involved. The website has free resources and toolkits that the hub has developed over the years with a range of community partners.

Participatory Research Group: http://participate2015.org/prg/

The Participatory Research Group (PRG) is a network of organisations committed to bringing knowledge from the margins into decision-making at every level of society. The website lists publications, including synthesis reports, research reviews and policy briefs, which draw together the findings of the PRG's research in 29 countries. It also showcases outcomes from creative participatory approaches, including visual research such as digital storytelling and participatory video.

Participatory Geographies Research Group (PyGyRG): http://www.pygyrg.co.uk/

PyGyRG is a collective whose members aim to raise the profile/perceived value, and further the understanding and use of participatory approaches, methods, tools and principles within academic geography and beyond. 


\section{References}

Ansell N (2001) Producing knowledge about 'Third World Women': The politics of fieldwork in a Zimbabwean secondary school. Ethics, Place and Environment 4(2): 101-116.

Baldwin M (2012) Participatory action research. In: Gray, M, Midgley J and Webb SA (eds) The SAGE Handbook of Social Work. Sage, London, p. 467-481.

Barreteau O, Bots PWG, Daniell KA (2010) A framework for clarifying "participation" in participatory research to prevent its rejection for the wrong reasons. Ecology and Society 15(2): 1-22.

Berger R (2015) Now I see it, now I don't: Researcher's position and reflexivity in qualitative research. Qualitative Research 15(2):219-234.

Bird D, Culley L and Lakhanpaul M (2013) Why collaborate with children in health research: An analysis of the risks and benefits of collaboration with children. Archives of Disease in Childhood: Education \& Practice Edition 1-7.

Cahill C (2007a) Including excluded perspectives in participatory action research. Design Studies 28(3): 325-340.

Cahill C (2007b) Doing research with young people: Participatory research and the rituals of collective work. Children's Geographies 5(3): 297-312.

Cammarota J, Fine M (2008) Youth participatory action research: A pedagogy for transformational resistance. In Cammarota J and Fine M (eds) Revolutionizing Education: Youth Participatory Action Research in Motion. Routledge: Oxon.

Chávez V, Soep E (2005) Youth radio and the pedagogy of collegiality. Harvard Educational Review 75(4): 409-434.

Christensen P, Prout A (2002) Working with ethical symmetry in social research with children. Childhood 9(4): 477-497. 
Clark A, Moss P (2001) Listening to Young Children: The Mosaic Approach. National Children's Bureau: London.

Clark A (2010) Young children as protagonists and the role of participatory, visual methods in engaging multiple perspectives. American Journal of Community Psychology 46(1-2): 115123.

Crivello G, Camfield L, Woodhead M (2009) How can children tell us about their wellbeing? Exploring the potential of participatory research approaches within young lives. Social Indicators Research 90(1): 51-72.

DeLemos JL (2006) Community-based participatory research: Changing scientific practice from research on communities to research with and for Communities. Local Environment 11(3): 329-338.

Dentith AM, Measor L, O'Malley MP. (2009). Stirring dangerous waters: Dilemmas for critical participatory research with young people. Sociology. 43(1): 158-168.

Dorozenko KP, Bishop BJ, Roberts LD (2016) Fumblings and faux pas: Reflections on attempting to engage in participatory research with people with an intellectual disability. Journal of Intellectual \& Developmental Disability 41(3): 197-208.

Flicker S (2008) Who benefits from community-based participatory research? A case study of the positive youth project. Health Education \& Behaviour 35(1):70-86.

Foth M, Azup J (2006) Participatory design and action research: Identical twins or synergetic pair? In Jacucci G, Kensing F, Wagner I and Blomberg J (eds.) Proceedings Participatory Design Conference 2006: Expanding Boundaries in Design 2. Trento: Italy. p. 93-96.

Franks M (2011) Pockets of participation: Revisiting child-centred Participation Research. Children \& Society 25(1): 15-25. 
Funk A, Borek NV, Taylor D, Grewal P, Tzemis D, Buxton JA (2012) Climbing the "ladder of participation": Engaging experiential youth in a participatory research project. Qualitative Research 103(4):288-292.

Gallacher L, Gallagher M (2008) Methodological immaturity in childhood research? Thinking through "participatory methods". Childhood 15(4):499-516.

Gallagher M (2008) 'Power is not an evil': Rethinking power in participatory methods. Children's Geographies 6(2): 137-150.

Graham A, Powell MA, Truscott J (2016) Exploring the nexus between participatory methods and ethics in early childhood. Australasian Journal of Early Childhood 41(1):82-89.

Grasser S, Schunko C, VogI CR (2016) Children as ethnobotanists: Methods and local impact of a participatory research project with children on wild plant gathering in the Grosses Walsertal Biosphere Reserve, Austria. Journal of Ethnobiology and Ethnomedicine 12(46):116.

Gristy C (2015) Engaging with and moving on from participatory research: A personal reflection. International Journal of Research \& Method in Education 38(4):371-387

Grover S (2004) Why won't they listen to us? On giving power and voice to children participating in social research Childhood 11(1): 81-93.

Guishard M (2009) The false paths, the endless labours, the turns now this way and now that: Participatory action research, mutual vulnerability, and the politics of inquiry. Urban Review 41(1):85-105.

Hart R (1992) Children's participation from tokenism to citizenship. UNICEF Innocenti Research Centre: Florence.

Hart R (1997) Children's Participation: The Theory And Practice Of Involving Young Citizens In Community Development And Environmental Care. Earthscan: London.

Hart J, Newman J, Ackerman L, Feeney T (2004) Children Changing their World: Understanding and Evaluating Children's Participation in Development. Woking: Plan International. 
Hill M (2006) Children's voices on ways of having a voice: Children's and young people's perspectives on methods used in research and consultation. Childhood 13(1): 69-90.

Ho PSY (2013) Researching with a broken arm: Finding sisterhood in injury. Sexualities 16(1/2):78-93.

Holland S, Renold E, Ross NJ, Hillman A (2010) Power, agency and participatory agendas: A critical exploration of young people's engagement in participative qualitative research. Childhood 17(3):360-375.

Holloway S Valentine G (2000) Children's Geographies: Playing, Living and Learning. Routledge: London.

Horowitz CR, Robinson M, Seifer S (2009) Community-based participatory research from the margin to the mainstream: Are researchers prepared? Circulation 119(19):2633-42.

Israel BA, Parker EA, Rowe Z, Salvatore A, Minkler M, López J, Butz A, Mosley A, Coates L, Lambert G, Potito PA, Brenner B, Rivera M, Romero H, Thompson B, Coronado G, Halstead S (2005) Community-based participatory research: lessons learned from the Centers for Children's Environmental Health and Disease Prevention Research. Environmental Health Perspectives 113(10):1463-1471.

Jacquez F, Vaugn LM, Wagner E (2013) Youth as partners, participants or passive recipients: A review of children and adolescents in community-based participatory research. American Journal of Community Psychology 51(1):176-189.

Jagosh J, Macaulay AC, Pluye P, Salsberg J, Bush PL, Henderson J, Sirett E, Wong G, Cargo M., Herbert, CP, Seifer, SD., Green, LW and Greenlaugh T (2012) Uncovering the benefits of participatory research: Implications of a realist review for health research and practice. The Milbank Quarterly 90(2):311-346.

Jagosh J, Bush PL, Salsberg J, Macaulay AC, Greenhalgh T, Wong G, Cargo M, Green LW, Herbert CP, Pluye P (2015) A realist evaluation of community-based participatory research: partnership synergy, trust building and related ripple effects. BMC Public Health 15(725):111. 
Kellett M, Forrest R, (aged ten), Dent M (aged ten), Ward S (aged ten) (2004) 'Just teach us the skills please, we'll do the rest': Empowering ten-year olds as active researchers. Children \& Society 18(5):329-343.

Khanlou N, Peter E (2005) Participatory action research: Considerations for ethical review. Social Science \& Medicine 60(10):2333-2340.

Langhout RD, Thomas E (2010) Imagining participatory research in collaboration with children: An introduction. American Journal of Community Psychology 46(1-2):60-66.

Le De L, Gaillard JC, Friesen W (2015) Academics doing participatory disaster research: how participatory is it? Environmental Hazards 14(1):1-15.

Lushey CJ, Munro ER (2014) Participatory peer research methodology: An effective method for obtaining young people's perspectives on transitions from care to adulthood? Qualitative Social Work 14(4):522-537.

Mason J, Danby S (2011) Children as experts in their lives: Child inclusive research. Child Indicators Research 4(2):185-189.

Mayan MJ, Daum CH (2016) Worth the risk? Muddled relationships in community-based participatory research. Qualitative Health Research 26(1):69-76.

McCartan C, Schubotz D. and Murphy J (2012) The self-conscious researcher - Post-modern perspectives of participatory research with young people. Forum: Qualitative Social Research 13(1):1-18.

Minkler M, Fadem P, Perry M, Blum K, Moore L, Rogers J (2002) Ethical dilemmas in participatory action research: A case study from the disability community. Health Education and Behavior 29(1):14-29.

Mohan G (1999) Not so distant, not so strange: The personal and the political in participatory research. Ethics, Place and Environment 2(1):41-54.

Morrow V (2008) Ethical dilemmas in research with children and young people about their social environments. Children's Geographies 6(1):49-61. 
Muhammad M, Wallerstein N, Sussman A.L, Avila M, Belone L, Duran B (2015) Reflections on researcher identity and power: The impact of positionality on community based participatory research (CBPR) processes and outcomes. Critical Sociology 41(7-8):1045-1063.

Noske-Turner J (2012) Making One Blood: A journey through participatory radio documentary production. Journal of Media Practice 13(2):177-187.

Orlowski SK, Lawn S, Venning A, Winsall M, Jones GM, Wyld K, Damarell RA, Antezana G, Schrader G, Smith D, Collin P, Bidargaddi N (2015) Participatory research as one piece of the puzzle: A systematic review of consumer involvement in design of technology-based youth mental health and well-being interventions. JMIR Human Factors 2(2):1-21.

Pain R (2003) Youth, age, and the representation of fear. Capital \& Class 27(2):151-171.

Pain R and Francis P (2003) Reflections on participatory research. Area 35(1):46-54.

Pain R (2004) Social geography: Participatory research. Progress in Human Geography 28(5):652-663.

Paradiso de Sayu R and Chanmugam A (2016) Perceptions of empowerment within and across partnerships in community-based participatory research: A dyadic interview analysis. Qualitative Health Research 26(1):105-116.

Pinter A and Zandian S (2015) 'I thought it would be tiny little one phrase that we said, in a huge big pile of papers:' Children's reflections on their involvement in participatory research. Qualitative Research 15(2):235-250.

Randall D (2012) Revisiting Mandell's 'least adult' role and engaging with children's voices in research. Nurse Researcher 19(3): 39-43.

Shier H (2001) Pathways to participation: Openings, opportunities and obligations. Children \& society 15(2): 107-117.

Shier H (2006) Pathways to Participation Revisited: Nicaragua perspective. New Zealand Association for Intermediate and Middle Schooling 2: 13-18. 
Sime D (2008) Ethical and methodological issues in engaging young people living in poverty with participatory research methods. Children's Geographies 6(1):63-78.

Sinclair R (2004) Participation in practice: Making it meaningful, effective and sustainable. Children \& society 18(2):106-118.

Smyth J and Mclnerney P (2013) Whose side are you on? Advocacy ethnography: some methodological aspects of narrative portraits of disadvantaged young people, in socially critical research. International Journal of Qualitative Studies in Education 26(1):1-20.

Sutton L (2009) 'They'd only call you a scally if you are poor': The impact of socio-economic status on children's identities. Children's Geographies 7(3):277-290.

Thomson F (2007) Are methodologies for children keeping them in their place? Children's Geographies 5(3):207-218.

Treseder P (1997) Empowering Children and Young People. London: Save the Children.

Tucker MT, Lewis Jr DW, Foster PP, Lucky F, Yerby LG, Hites L, Higginbottom JC (2016) Community-based participatory research - speed dating: An innovative model for fostering collaborations between community leaders and academic researchers. Health Promotion Practice 17(2):775-780.

United Nations (1989) Convention on the Rights of the Child. Available at: http://353ld710iigr2n4po7k4kgvv-wpengine.netdna-ssl.com/wpcontent/uploads/2010/05/UNCRC_PRESS200910web.pdf. [Accessed 12/01/2017].

Vromen A (2003) People try to put us down...participatory citizenship of generation $\mathrm{x}$. Australian Journal of Political Science 43(1):79-97.

Waller T, Bitou A (2011) Research with children: Three challenges for participatory research in early childhood. European Early Childhood Education Research Journal 19(1):5-20.

Warin J (2011) Ethical mindfulness and reflexivity: Managing a research relationship with children and young people in a 14-year qualitative longitudinal research (QLR) study. Qualitative Inquiry 17(2):805-814. 
Weller S (2006) Tuning-in to teenagers! Using radio phone-in discussions in research with young people. International Journal of Social Research Methodology 9(4):303-315.

Wilkinson S (2015) Young People, Alcohol and Urban Life. PhD Thesis. University of Manchester.

Wilkinson C (2015) Connecting Communities through Youth-led Radio. PhD Thesis. University of Liverpool.

Wilkinson C (2016) Babe, I like your lipstick: Rethinking researcher personality and appearance Children's Geographies 14(1):115-123.

Wright D, Corner J, Hopkinson J, Foster C (2006) Listening to the views of people affected by cancer about cancer research: An example of participatory research in setting the cancer research agenda. Health Expectations 9(1):3-12. 